\title{
Impact of Sarcopenia on Two-Year Mortality in Patients with HCV-Associated Hepatocellular Carcinoma After Radiofrequency Ablation
}

\author{
Ahmed Salman (1) \\ Mohamed Salman ${ }^{2}$ \\ Ahmed Moustafa (iD ${ }^{3}$ \\ Hossam El-Din Shaaban (ID) \\ Ahmed El-Mikkawy ${ }^{5}$ \\ Safa Labib' \\ Ahmed Youssef ${ }^{\prime}$ \\ Mahmoud Gouda Omar (D) \\ Mohamed Matter ${ }^{6}$ \\ Hesham Elkassar ${ }^{\prime}$ \\ 'Internal Medicine Department, Faculty \\ of Medicine, Cairo University, Cairo, \\ Egypt; ${ }^{2}$ General Surgery Department, \\ Faculty of Medicine, Cairo University, \\ Cairo, Egypt; ${ }^{3}$ Department of Endemic \\ Medicine and Hepatology, Faculty of \\ Medicine, Cairo University, Cairo, Egypt; \\ ${ }^{4}$ Gastroenterology Department, National \\ Hepatology and Tropical Medicine \\ Research Institute, Cairo, Egypt; \\ ${ }^{5}$ Hepatology and Gastroenterology \\ Department, Theodor Bilharz Research \\ Institute, Cairo, Egypt; ${ }^{6}$ Radiodiagnosis \\ Department, Faculty of Medicine, Alazhar \\ University, Cairo, Egypt
}

Purpose: Radiofrequency ablation (RFA) appears effective for the treatment of hepatocellular carcinoma (HCC). Evaluation of prognostic factors is imperative for patient selection and improving treatment efficacy. This study aimed to assess sarcopenia as a predictor of the outcome of RFA in patients with HCC.

Methods: This prospective study included all patients with HCC on top of HCV-related cirrhosis who underwent RFA and followed up for a minimum of two years. CT scan was used to determine the skeletal muscle index at the psoas, erector spinae, quadratus lumborum, transversus abdominis, external and internal obliques, and rectus abdominis muscles. Cross-sectional areas were calculated to obtain a lumbar skeletal muscle index (L3-SMI).

Results: A total of 97 patients were enrolled in the study. The L3-SMI was $46.2 \pm 12.1 \mathrm{~cm}^{2} / \mathrm{m}^{2}$. Older age was the only risk factor associated with sarcopenia $(p=0.001)$. The overall survival at two years for the whole group was $65.2 \%$. Sarcopenia and MELD score were independent predictors of OS at two years with HR of 7.6 (95\% CI: 3.1-18.7) and 2.2 (95\% CI: $1.0-4.8$ ), respectively. Recurrence-free survival was $84.1 \%$ at two years. Recurrence was not affected by all factors, including sarcopenia.

Conclusion: Sarcopenia is a surrogate predictor of overall survival at two years in HCC patients after RFA. Sarcopenia assessment might be an additional prognostic indicator with conventional biomarkers to optimize the selection criteria for receiving RFA for early-stage HCC.

Keywords: sarcopenia, mortality, hepatocellular carcinoma, radiofrequency ablation

\section{Introduction}

Worldwide, hepatocellular carcinoma (HCC) is the 7th most common cancer and the 3rd leading cause of cancer-related deaths with an obvious heterogeneous geographical distribution. In Egypt, HCC is the most common cancer in Egyptian males. ${ }^{1}$ Many surgical and non-surgical approaches are available for the treatment of HCC. Non-surgical therapy includes local tumor ablation, transarterial embolization, and radiotherapy. ${ }^{2}$ Radiofrequency ablation (RFA) appears to be a local curative treatment of small HCC lesions $\left(<3 \mathrm{~cm}\right.$ in diameter). ${ }^{3}$ Existing literature reported promising long-term effectiveness of RFA treatment. ${ }^{4-6}$ However, the evaluation of prognostic factors is imperative for patient selection and improving treatment efficacy.

Sarcopenia is a progressive and generalized skeletal muscle disease characterized by accelerated loss of muscle mass and function. ${ }^{7}$ It has been associated with
Correspondence: Ahmed Salman Internal Medicine Department, Faculty of Medicine, Cairo University, I IO L Hadayek Alahram, II3 II, Cairo, Egypt Tel +20l000468664

Email awea844@gmail.com 
higher mortality among the general population ${ }^{8,9}$ and patients with cancer. ${ }^{8-10}$ Prevalence of sarcopenia varies widely from 1 to $29 \%$ among older people. ${ }^{11}$ Risk factors other than age include sex ${ }^{12}$ and inflammatory disease. ${ }^{13}$ Cancer patients are at risk of losing muscle mass due to anorexia, reduced physical activity, and aggressive treatment modalities. ${ }^{14,15}$ So far, sarcopenia's effect on the outcome of RFA as a curative treatment of HCC is poorly investigated. $^{16}$

This study aimed to assess the possible role of sarcopenia in predicting the outcome of radiofrequency ablation in patients with $\mathrm{HCC}$.

\section{Subjects and Methods}

This prospective study included a consecutive sample of all patients with HCC who underwent RFA from August 2015 to April 2018. All patients were followed up for a minimum of two years after RFA. All patients gave informed consent for using their clinical, laboratory, and radiological data at the time of the first examination. The study protocol conformed to the Declaration of Helsinki (1975) and was approved by the local institutional review board. All organs were donated voluntarily with written informed consent, and that this was conducted in accordance with the Declaration of Istanbul.

In the current study, we recruited only patient with $\mathrm{HCV}$-induced liver cirrhosis, and excluded patients with cirrhosis due to other etiologies, such as HBV, alcoholic liver diseases. The aim of this was to unify the studied population, as $\mathrm{HCV}$-induced liver cirrhosis is the most prevalent cause of liver cirrhosis and HCC is Egypt.

Cirrhosis, diagnosed either by histology or clinically, was graded according to the Child-Turcotte-Pugh (CTP) classification and Model for End-stage Liver Disease (MELD) scores as liver impairment measures. HCC was diagnosed according to criteria of the American Association for the Study of Liver Disease ${ }^{17}$ and staged by abdominal contrast-enhanced dynamic CT scan or gadolinium-enhanced magnetic resonance imaging (MRI). Moreover, each patient underwent a chest X-ray/ $\mathrm{CT}$ scan and bone scanning, as requested by the treating physicians.

Radiofrequency ablation was performed if the patient is a candidate for liver-directed procedures and meets the resectability criteria. These are liver-only disease and a single tumor $<4 \mathrm{~cm}$ in diameter with a CTP class A or B.

Initial data collection included age, sex, pre-treatment anthropometric features, laboratory findings including serum albumin, creatinine, international normality ratio (INR), complete blood picture, and alpha-fetoprotein (AFP), and dry weight body mass index (BMI). All data were obtained within two weeks before the RFA session. Follow-up ended after two years or upon patients' death.

\section{Image Analysis and Treatment Modality}

CT scans were obtained routinely at baseline for tumor staging purposes within two weeks before initiating treatment and used to determine the skeletal muscle index (SMI). A transverse image at the level of L3 was chosen from each scan. Muscles at this level include psoas, erector spinae, quadratus lumborum, transversus abdominis, external and internal obliques, and the rectus abdominis. $^{18}$ Obtained images were analyzed with SliceOmatic V 5.0 software (Tomovision, Montreal, Quebec, Canada), enabling specific tissue selection using previously determined Hounsfield units (HU). Skeletal muscle is selected and quantified by thresholds between -29 to +150 HU. ${ }^{19}$ These specific thresholds permit skeletal muscle assessment regardless of ascites in patients with cirrhosis, excluding muscular fat infiltration in the selected section. Two trained physicians checked all CT images. Cross-sectional areas were calculated and normalized for height as reported elsewhere $^{20}$ to obtain a lumbar skeletal muscle index (L3-SMI).

The MRI imaging data were excluded to avoid methodological heterogeneity. L3-SMI was expressed in $\mathrm{cm}^{2} / \mathrm{m}^{2}$. L3SMI was considered to indicate sarcopenia if $\leq 53 \mathrm{~cm}^{2} / \mathrm{m}^{2}$ in males with a BMI $\geq 25$ or $\leq 43 \mathrm{~cm}^{2} / \mathrm{m}^{2}$ with a $\mathrm{BMI}<25$, and $\leq 41 \mathrm{~cm}^{2} / \mathrm{m}^{2}$ in women. ${ }^{21}$

\section{Statistical Analysis}

Statistical analysis was done using IBMC SPSSC Statistics version 23 (IBM(C) Corp., Armonk, NY, USA). Numerical data were expressed as mean and standard deviation or median and range as appropriate. Qualitative data were expressed as frequency and percentage. Chisquare test was used to examine the relation between qualitative variables. For quantitative data, comparison between two groups was made using independent sample $t$-test or Mann-Whitney test. Survival analysis was done using Kaplan-Meier method and comparison between two survival curves was done using Log rank test. Multivariate analysis was done using Cox proportional-hazards model for factors affecting survival on univariate analysis. Hazard ratio (HR) with it $95 \%$ confidence interval (CI) 
were used for hazard estimation. A p-value $<0.05$ was considered significant.

\section{Results}

A total of 97 patients were enrolled in the study. Baseline and disease characteristics of the studied group are shown in Table 1, and laboratory findings in Table 2.

The L3-SMI of the whole studied group was 46.2 $\pm 12.1 \mathrm{~cm}^{2} / \mathrm{m}^{2}$. Sarcopenia was diagnosed in 42 patients (43.3\%). Table 3 shows a comparison between the Sarcopenia group $(n=42)$ and those with normal muscle mass (Non-Sarcopenia group, $\mathrm{n}=55$ ) regarding patients and disease factors. The only associated risk factor was older age in the sarcopenic group $(\mathrm{p}=0.001)$.

During follow-up, 3 cases underwent transarterial chemoembolization, and 2 underwent transarterial radioembolization. Liver transplantation was done for 16 patients. At the end of follow-up, 33 patients died. Causes of death are

Table I Baseline and Clinical Characteristics of the Studied Group ( $\mathrm{n}=97)$

\begin{tabular}{|l|c|}
\hline & Value \\
\hline Age (years) & $53.4 \pm 6.0$ \\
Sex (male/female) & $72 / 25$ \\
Body mass index $\left(\mathrm{kg} / \mathrm{m}^{2}\right)$ & $26.2 \pm 3.3$ \\
Diabetes mellitus & $22(22.7 \%)$ \\
Hypertension & $31(32.0 \%)$ \\
Dyslipidemia & $19(19.6 \%)$ \\
Active hepatitis C viral infection & $15(15.4 \%)$ \\
\hline Disease Characteristics & \\
Tumor diameter (cm) & $2.7 \pm 0.7$ \\
Child-Turcotte-Pugh class (A/B) & $64 / 33$ \\
Model for End-stage Liver Disease score & $10(8-15)$ \\
\hline
\end{tabular}

Note: Data are expressed as mean \pm SD, number (\%), or median (range).

Table 2 Laboratory Results of the Studied Group ( $n=97)$

\begin{tabular}{|l|c|}
\hline & Value \\
\hline Hemoglobin concentration $(\mathrm{gm} / \mathrm{dL})$ & $11.2 \pm 1.3$ \\
White cell count $\left(\times 10^{3} / \mathrm{mm}^{3}\right)$ & $6.3 \pm 1.9$ \\
Platelet count $\left(\times 10^{3} / \mathrm{mm}^{3}\right)$ & $177 \pm 59$ \\
Serum Albumin $(\mathrm{g} / \mathrm{dL})$ & $3.4 \pm 0.4$ \\
Serum Bilirubin $(\mathrm{mg} / \mathrm{dL})$ & $1.7 \pm 0.3$ \\
Alanine aminotransferase $(\mathrm{U} / \mathrm{L})$ & $49.9 \pm 14.3$ \\
Aspartate aminotransferase $(\mathrm{U} / \mathrm{L})$ & $59.4 \pm 11.6$ \\
International normalized ratio & $1.5 \pm 0.2$ \\
Serum creatinine $(\mathrm{mg} / \mathrm{dL})$ & $1.1 \pm 0.3$ \\
Alpha-fetoprotein $(\mathrm{ng} / \mathrm{mL})$ & $158(20-432)$ \\
\hline
\end{tabular}

Note: Data are expressed as mean $\pm S D$, or median (range). shown in Table 4. The cumulative survival proportion at two years for the whole group $(\mathrm{n}=97)$ was $65.2 \%$. Table 5 shows factors affecting overall survival. Sarcopenia was the only factor positively associated with worse survival at two-years (36.6\% vs $85.5 \%$ for non-sarcopenic patients, $\mathrm{p}<0.001)$. MELD score was near significance on univariate analysis $(p=0.053)$. On multivariate analysis, sarcopenia and MELD score were the only independent predictors of overall survival (Table 6). Sarcopenia carries a nearly 8 -fold higher risk of death within 2 years. As a continuous variable, L3-SMI significantly affected overall survival in males, but not in females (Table 7). In males, higher SMI was associated with better survival with a HR of 0.95 (95\% CI: 0.91-0.98).

During follow up, 12 patients developed local recurrence. Recurrence-free survival was $84.1 \%$ at two years. Table 8 shows the factors associated with recurrence-free survival (RFS). RFS was not affected by all factors, including sarcopenia.

\section{Discussion}

The study demonstrated that sarcopenia was a common occurrence in patients with HCC treated by RFA, affecting $43.3 \%$ of them. Older age was the only factor associated with a higher frequency of sarcopenia. The overall survival of these patients at two years was $65.2 \%$ and recurrence-free survival was $84.1 \%$. Sarcopenia was a surrogate predictor of overall survival at two years with a hazard ratio of 7.6 (95\% CI: 3.1-18.8). On the other hand, there was no association between sarcopenia and disease recurrence in this series.

In Egypt, $\mathrm{HCC}$ is considered the most challenging health problem. According to recent statistical data, HCC is the most common cancer in Egyptian males. ${ }^{1}$ Many studies described a rising incidence of HCC, which could be attributed to better diagnostic and screening programs, increasing incidence of $\mathrm{HCV}$ and cirrhosis, and longer life expectancy of cirrhotic patients. ${ }^{22}$ Therefore, identifying patients with a high-mortality risk is an essential step to select the most satisfactory treatment for each patient according to his/her prognosis. Great efforts have been made in this respect that developed many prognostic staging systems. However, prognostic factors for $\mathrm{HCC}$ remain controversial. Assessment of general performance and nutritional and functional status of HCC patients can improve the predictive yield of existing staging systems.

A recent review found that many factors have been suggested to affect the survival of patients with HCC who 
Table 3 Comparison Between Patients with and without Sarcopenia Regarding Possible Risk Factors

\begin{tabular}{|c|c|c|c|}
\hline & Sarcopenia Group $n=42$ & Non-Sarcopenia Group n=55 & p-value \\
\hline Age (years) & $55.6 \pm 5.0$ & $51.7 \pm 6.2$ & 0.001 \\
\hline Sex (male/female) & $28 / 14$ & $44 / 11$ & 0.137 \\
\hline Body mass index $\left(\mathrm{kg} / \mathrm{m}^{2}\right)$ & $26.5 \pm 3.5$ & $25.9 \pm 3.1$ & 0.346 \\
\hline Diabetes mellitus (yes/no) & $9 / 33$ & $13 / 42$ & 0.797 \\
\hline Hypertension (yes/no) & $13 / 29$ & $18 / 37$ & 0.853 \\
\hline Dyslipidemia (yes/no) & $9 / 33$ & $10 / 45$ & 0.690 \\
\hline \multicolumn{4}{|l|}{ Disease Characteristics } \\
\hline Tumor diameter $(\mathrm{cm})$ & $2.8 \pm 0.8$ & $2.7 \pm 0.7$ & 0.687 \\
\hline Child Class (A/B) & $27 / 15$ & $37 / 18$ & 0.758 \\
\hline MELD score & $10(8-15)$ & $10(8-13)$ & 0.365 \\
\hline \multicolumn{4}{|l|}{ Laboratory results } \\
\hline Hemoglobin concentration $(\mathrm{gm} / \mathrm{dL})$ & $11.2 \pm 1.2$ & $11.2 \pm 1.5$ & 0.993 \\
\hline White cell count $\left(\times 10^{3} / \mathrm{mm}^{3}\right)$ & $6.3 \pm 2.2$ & $6.2 \pm 1.6$ & 0.855 \\
\hline Platelet count $\left(\times 10^{3} / \mathrm{mm}^{3}\right)$ & $|74 \pm 6|$ & $180 \pm 57$ & 0.642 \\
\hline Serum Albumin $(g / d L)$ & $3.4 \pm 0.3$ & $3.4 \pm 0.4$ & 0.841 \\
\hline Serum Bilirubin (mg/dL) & $1.6 \pm 0.3$ & $1.7 \pm 0.4$ & 0.005 \\
\hline Alanine aminotransferase $(\mathrm{U} / \mathrm{L})$ & $49.1 \pm 13.6$ & $50.5 \pm 14.8$ & 0.637 \\
\hline Aspartate aminotransferase $(\mathrm{U} / \mathrm{L})$ & $60.3 \pm 12.5$ & $58.8 \pm 10.9$ & 0.525 \\
\hline International normalized ratio & $1.5 \pm 0.2$ & $1.4 \pm 0.2$ & 0.258 \\
\hline Serum creatinine $(\mathrm{mg} / \mathrm{dL})$ & $1.1 \pm 0.3$ & $1.1 \pm 0.3$ & 0.669 \\
\hline Alpha-fetoprotein $(\mathrm{ng} / \mathrm{mL})$ & $154(45-432)$ & $165(20-301)$ & 0.626 \\
\hline
\end{tabular}

Note: Data are expressed as mean $\pm \mathrm{SD}$, or median (range).

Abbreviation: MELD, Model for End-stage Liver Disease.

Table 4 Causes of Death in 33 Patients

\begin{tabular}{|l|c|}
\hline Cause & Number (\%) \\
\hline Liver cell Failure & $9(27.3 \%)$ \\
Sepsis & $9(27.3 \%)$ \\
Metastases & $7(21.2 \%)$ \\
Hematemesis & $4(12.1 \%)$ \\
Myocardial infarction & $2(6.1 \%)$ \\
Pulmonary embolism & $1(3.0 \%)$ \\
Accident & $1(3.0 \%)$ \\
\hline
\end{tabular}

underwent RFA. These prognostic factors include liver function as CTP class, high serum levels of AFP, and the presence of portosystemic collaterals. $^{23}$ In the current study, we investigated the prognostic significance of sarcopenia in patients with early-stage HCC treated with RFA. All patients in the present study developed HCC on top of HCV-associated cirrhosis. This particular group is impressive because chronic liver diseases are considered a risk factor for sarcopenia. ${ }^{24}$ A recent systematic review of 13 studies including 3111 patients indicated a significant association between sarcopenia and all-cause mortality with a pooled adjusted hazard ratio of $1.95(95 \% \mathrm{CI}: 1.60-2.37) .{ }^{25}$ Comparable to the present study, most studies did not find an association between sarcopenia and $\mathrm{HCC}$ recurrence. ${ }^{25}$

Sarcopenia has gained increasing interest as a preoperative prognostic indicator in many cancer types. $^{21,26,27}$ Previous studies identified sarcopenia as a predictor of poor survival of HCC patients undergoing liver resection. ${ }^{28-31}$ However, few studies investigated the impact of sarcopenia on the outcome of RFA. One study included patients subjected to RFA $(n=29)$ or surgical resection $(n=61)$. The authors reported impaired overall survival in sarcopenic patients with no difference between resection and RFA. The presence of sarcopenia did not affect recurrence. ${ }^{32}$ Another study said that low pre-treatment muscle mass was an independent predictor for survival. They evaluated muscle mass using the psoas muscle index (PMI, $\mathrm{cm}^{2} / \mathrm{m}^{2}$ ) on CT images. ${ }^{33}$ Yeh et al studied the prognostic role of pre-sarcopenia in patients treated with RFA. They defined pre-sarcopenia as psoas muscle area index $<$ 4.24 and $2.50 \mathrm{~cm}^{2} / \mathrm{m}^{2}$ for males and females, respectively. The authors concluded that pre-sarcopenia is the prognostic factor of overall survival, but not of recurrence in early-stage HCC patients undergoing RFA. ${ }^{34}$ 
Table 5 Factors Associated with Overall Survival at 2 Years in the Studied Group

\begin{tabular}{|c|c|c|c|c|c|}
\hline & & $\mathbf{n}$ & Events & $\begin{array}{l}\text { Cumulative } \\
\text { Survival } \\
\text { Proportion } \\
\text { (\%) }\end{array}$ & p-value \\
\hline Sarcopenia & $\begin{array}{l}\text { Yes } \\
\text { No }\end{array}$ & $\begin{array}{l}42 \\
55\end{array}$ & $\begin{array}{c}25 \\
8\end{array}$ & $\begin{array}{l}36.6 \\
85.5\end{array}$ & $<0.001$ \\
\hline Age (years) & $\begin{array}{l}>50 \\
\leq 50\end{array}$ & $\begin{array}{l}66 \\
31\end{array}$ & $\begin{array}{c}24 \\
9\end{array}$ & $\begin{array}{l}62.0 \\
71.0\end{array}$ & 0.473 \\
\hline Recurrence & $\begin{array}{l}\text { Yes } \\
\text { No }\end{array}$ & $\begin{array}{l}12 \\
85\end{array}$ & $\begin{array}{c}7 \\
26\end{array}$ & $\begin{array}{l}41.7 \\
68.6\end{array}$ & 0.122 \\
\hline Sex & $\begin{array}{l}\text { Male } \\
\text { Female }\end{array}$ & $\begin{array}{l}72 \\
25\end{array}$ & $\begin{array}{l}23 \\
10\end{array}$ & $\begin{array}{l}67.0 \\
60.0\end{array}$ & 0.599 \\
\hline Diabetes mellitus & $\begin{array}{l}\text { Yes } \\
\text { No }\end{array}$ & $\begin{array}{l}22 \\
75\end{array}$ & $\begin{array}{c}6 \\
27\end{array}$ & $\begin{array}{l}72.7 \\
62.7\end{array}$ & 0.432 \\
\hline Tumor size $(\mathrm{cm})$ & $\begin{array}{l}>2 \\
\leq 2\end{array}$ & $\begin{array}{l}79 \\
18\end{array}$ & $\begin{array}{c}28 \\
5\end{array}$ & $\begin{array}{l}63.7 \\
72.2\end{array}$ & 0.536 \\
\hline Child Class & $\begin{array}{l}\text { A } \\
B\end{array}$ & $\begin{array}{l}64 \\
33\end{array}$ & $\begin{array}{l}22 \\
11\end{array}$ & $\begin{array}{l}64.5 \\
66.7\end{array}$ & 0.995 \\
\hline MELD score & $\begin{array}{l}>9 \\
\leq 9\end{array}$ & $\begin{array}{l}56 \\
41\end{array}$ & $\begin{array}{l}15 \\
18\end{array}$ & $\begin{array}{l}72.0 \\
65.1\end{array}$ & 0.053 \\
\hline Transplantation & $\begin{array}{l}\text { Yes } \\
\text { No }\end{array}$ & $\begin{array}{l}16 \\
81\end{array}$ & $\begin{array}{c}4 \\
29\end{array}$ & $\begin{array}{l}60.9 \\
64.2\end{array}$ & 0.419 \\
\hline ALBI Grade & $\begin{array}{l}\text { G1 } \\
\text { G2 }\end{array}$ & $\begin{array}{l}66 \\
31\end{array}$ & $\begin{array}{l}21 \\
12\end{array}$ & $\begin{array}{l}68.2 \\
59.6\end{array}$ & 0.474 \\
\hline S. Creatinine ( $\mathrm{mg} / \mathrm{dL})$ & $\begin{array}{l}>1.2 \\
\leq 1.2\end{array}$ & $\begin{array}{l}20 \\
77\end{array}$ & $\begin{array}{c}4 \\
29\end{array}$ & $\begin{array}{l}80.0 \\
61.4\end{array}$ & 0.158 \\
\hline Hemoglobin (gm/dL) & $\begin{array}{l}<12 \\
\geq 12\end{array}$ & $\begin{array}{l}69 \\
28\end{array}$ & $\begin{array}{c}24 \\
9\end{array}$ & $\begin{array}{l}64.2 \\
67.9\end{array}$ & 0.748 \\
\hline ALT (U/L) & $\begin{array}{l}>55 \\
\leq 55\end{array}$ & $\begin{array}{l}29 \\
68\end{array}$ & $\begin{array}{c}8 \\
25\end{array}$ & $\begin{array}{l}72.2 \\
62.0\end{array}$ & 0.329 \\
\hline AST (U/L) & $\begin{array}{l}>40 \\
\leq 40\end{array}$ & $\begin{array}{c}92 \\
5\end{array}$ & $\begin{array}{c}31 \\
2\end{array}$ & $\begin{array}{l}65.4 \\
60.0\end{array}$ & 0.756 \\
\hline INR & $\begin{array}{l}>1.1 \\
\leq 1.1\end{array}$ & $\begin{array}{c}93 \\
4\end{array}$ & $\begin{array}{c}31 \\
2\end{array}$ & $\begin{array}{l}65.8 \\
50.0\end{array}$ & 0.369 \\
\hline
\end{tabular}

Abbreviations: MELD, Model for End-stage Liver Disease; ALBI, albumin-bilirubin grade; ALT, alanine aminotransferase; AST, aspartate aminotransferase; INR, international normalized ratio.

In the current study, $43.3 \%$ of the patients had sarcopenia. Previous studies have reported a widely variable frequency of sarcopenia in patients with $\mathrm{HCC}$ ranging from $12.4 \%$ to $66.3 \%{ }^{25}$ The only factor positively associated with sarcopenia was older age. However, the study sample was relatively younger than that reported in studies investigating the link between sarcopenia and RFA outcome. For example, $78 \%$ of patients in Yuri's study ${ }^{33}$
Table 6 Multivariate Cox Proportional Hazards Model for Factors Affecting Overall Survival

\begin{tabular}{|l|r|r|r|r|r|}
\hline & \multicolumn{1}{|c|}{ B } & \multirow{2}{*}{ p-value } & HR & \multicolumn{2}{|c|}{$\mathbf{9 5 \%}$ Cl for HR } \\
\cline { 5 - 6 } & & & & Lower & Upper \\
\hline Sarcopenia & 2.026 & $<0.00 I$ & 7.59 & 3.07 & 18.77 \\
MELD score > 9 & 0.800 & 0.040 & 2.23 & 1.04 & 4.78 \\
Child Score B vs A & 0.116 & 0.783 & 1.12 & 0.49 & 2.56 \\
Age > 50 years & 0.585 & 0.201 & 1.79 & 0.73 & 4.40 \\
Size > 2 cm & 0.210 & 0.673 & 1.23 & 0.47 & 3.26 \\
ALBI G2 vs GI & 0.533 & 0.183 & 1.70 & 0.78 & 3.74 \\
\hline
\end{tabular}

Abbreviations: $\mathrm{B}$, regression coefficient; $\mathrm{HR}$, hazard ratio; $\mathrm{Cl}$, confidence interval; MELD, Model for End-stage Liver Disease; ALBI, albumin-bilirubin grade.

Table 7 Cox Proportional Hazards Model for Overall Survival and L3-SMI in Males and Females

\begin{tabular}{|l|c|l|l|c|r|}
\hline \multirow{2}{*}{ L3-SMI } & \multirow{2}{*}{ B } & \multirow{2}{*}{ p-value } & \multirow{2}{*}{ HR } & \multicolumn{2}{|c|}{$95.0 \%$ CI for HR } \\
\cline { 4 - 6 } & & & & Lower & Upper \\
\hline Males & -0.053 & 0.005 & 0.95 & 0.91 & 0.98 \\
Females & -0.052 & 0.118 & 0.95 & 0.89 & 1.01 \\
\hline
\end{tabular}

Abbreviations: $B$, regression coefficient; $\mathrm{HR}$, hazard ratio; $\mathrm{Cl}$, confidence interval; SMI, skeletal muscle index.

were $>60$ years, compared to only $9 \%$ in the current study. The mean age in Yeh's study ${ }^{34}$ was $63.4 \pm 10.1$ years, while in the present study, it was $53.4 \pm 6.0$ years. The younger age in the current study supports the concept that sarcopenia is an independent predictor of poor survival, even in younger patients. The young age also indicates the importance of chronic liver disease in the development of sarcopenia. It was reported to affect $30 \%$ to $70 \%$ of patients with cirrhosis. ${ }^{24}$

The pathogenesis of sarcopenia in cirrhosis is poorly explained, but suggested mechanisms have been proposed indicating an imbalance between muscle breakdown and formation. It is proposed to be affected by protein catabolism and hormonal and metabolic alteration leading to muscle depletion. ${ }^{24,35}$ These factors may predispose to poor survival in patients with $\mathrm{HCC}^{36}$ Another mechanism may involve decreased insulin-like growth factor-1 (IGF-1), strongly associated with low muscle mass and strength. ${ }^{37}$ It has been reported that low plasma IGF-1 in HCC patients is associated with poor overall survival. ${ }^{38}$ Sarcopenia was also linked to the tumor necrosis factor- $\alpha$ system, which may enhance tumor migration and invasion in HCC. ${ }^{39}$

Many methods are available for the evaluation of skeletal muscle mass. These include dual-energy X-ray absorptiometry and bioelectrical impedance analysis. 
Table 8 Factors Associated with Recurrence-Free Survival at Two Years in the Studied Group

\begin{tabular}{|c|c|c|c|c|c|}
\hline & & $\mathbf{n}$ & Events & $\begin{array}{l}\text { Cumulative } \\
\text { Survival } \\
\text { Proportion } \\
\text { (\%) }\end{array}$ & p-value \\
\hline Sarcopenia & $\begin{array}{l}\text { Yes } \\
\text { No }\end{array}$ & $\begin{array}{l}42 \\
55\end{array}$ & $\begin{array}{l}6 \\
6\end{array}$ & $\begin{array}{l}76.5 \\
88.0\end{array}$ & 0.176 \\
\hline Age (years) & $\begin{array}{l}>50 \\
\leq 50\end{array}$ & $\begin{array}{l}66 \\
31\end{array}$ & $\begin{array}{l}8 \\
4\end{array}$ & $\begin{array}{l}83.9 \\
84.7\end{array}$ & 0.984 \\
\hline Sex & $\begin{array}{l}\text { Male } \\
\text { Female }\end{array}$ & $\begin{array}{l}72 \\
25\end{array}$ & $\begin{array}{l}10 \\
2\end{array}$ & $\begin{array}{l}82.4 \\
89.2\end{array}$ & 0.461 \\
\hline Diabetes mellitus & $\begin{array}{l}\text { Yes } \\
\text { No }\end{array}$ & $\begin{array}{l}22 \\
75\end{array}$ & $\begin{array}{l}4 \\
8\end{array}$ & $\begin{array}{l}77.8 \\
86.3\end{array}$ & 0.453 \\
\hline Child Class & $\begin{array}{l}\text { A } \\
B\end{array}$ & $\begin{array}{l}64 \\
33\end{array}$ & $\begin{array}{l}10 \\
2\end{array}$ & $\begin{array}{l}81.0 \\
90.7\end{array}$ & 0.214 \\
\hline MELD score & $\begin{array}{l}>9 \\
\leq 9\end{array}$ & $\begin{array}{l}56 \\
41\end{array}$ & $\begin{array}{l}6 \\
6\end{array}$ & $\begin{array}{l}86.8 \\
80.9\end{array}$ & 0.341 \\
\hline ALBI Grade & $\begin{array}{l}\text { G1 } \\
\text { G2 }\end{array}$ & $\begin{array}{l}66 \\
31\end{array}$ & $\begin{array}{l}9 \\
3\end{array}$ & $\begin{array}{l}82.9 \\
87.0\end{array}$ & 0.624 \\
\hline S. Creatinine $(\mathrm{mg} / \mathrm{dL})$ & $\begin{array}{l}>1.2 \\
\leq 1.2\end{array}$ & $\begin{array}{l}20 \\
77\end{array}$ & $\begin{array}{l}3 \\
9\end{array}$ & $\begin{array}{l}83.0 \\
84.6\end{array}$ & 0.853 \\
\hline Hemoglobin (gm/dL) & $\begin{array}{l}<12 \\
\geq 12\end{array}$ & $\begin{array}{l}69 \\
28\end{array}$ & $\begin{array}{l}7 \\
5\end{array}$ & $\begin{array}{l}86.9 \\
77.9\end{array}$ & 0.382 \\
\hline ALT (U/L) & $\begin{array}{l}>55 \\
\leq 55\end{array}$ & $\begin{array}{l}29 \\
68\end{array}$ & $\begin{array}{l}5 \\
7\end{array}$ & $\begin{array}{l}78.8 \\
87.0\end{array}$ & $0.48 I$ \\
\hline AST (U/L) & $\begin{array}{l}>40 \\
\leq 40\end{array}$ & $\begin{array}{l}92 \\
5\end{array}$ & $\begin{array}{l}12 \\
0\end{array}$ & $\begin{array}{l}83.4 \\
100.0\end{array}$ & 0.434 \\
\hline INR & $\begin{array}{l}>1.1 \\
\leq 1.1\end{array}$ & $\begin{array}{l}93 \\
4\end{array}$ & $\begin{array}{l}12 \\
0\end{array}$ & $\begin{array}{l}83.6 \\
100.0\end{array}$ & 0.520 \\
\hline
\end{tabular}

Abbreviations: MELD, Model for End-stage Liver Disease; ALBI, albumin-bilirubin grade; Hb, hemoglobin; ALT, alanine aminotransferase; AST, aspartate aminotransferase; INR, international normalized ratio.

Currently, CT is considered the gold standard for sarcopenia evaluation owing to its accuracy and wide availability. ${ }^{40}$ Different CT methods are used to measure muscle mass. Like the present study, many investigators quantified sarcopenia by measuring muscle mass at the level of L3 vertebra on 2D planar sections of CT scans. This method has been recognized as the most accurate predictor of whole-body muscle mass ${ }^{41}$ and is accepted as a marker of sarcopenia and cachexia. ${ }^{42}$ Previous studies also showed a good correlation between total muscle area and psoas muscle area at the middle of the third lumbar vertebra level. ${ }^{43}$

In this series, the overall survival at two years was about $65.2 \%$. This figure is a bit lower than some previous studies. ${ }^{44-46}$ This may be attributed to inclusion of postHVC induced cirrhotic cases only in the current study. The most common causes of death were liver failure and sepsis $(\mathrm{n}=9,27.3 \%$ for both), followed by metastases $(21.2 \%)$

There are some limitations to our study. First, we did not measure muscle strength or physical function in our patients. However, muscle mass loss is potentially associated with muscle strength decline. Studies are needed to incorporate muscle power or functional status, which would be as important as muscle mass for defining sarcopenia. Secondly, the follow-up period was relatively short and the sample size was quite small. HCV cirrhosis in many Egyptian patients is well known to be associated with a previous history of nosocomial HCV infection from parenteral mass treatment for schistosomiasis, a disease that is commonly associated with muscle wasting. Further studies should put this point into consideration in addition to the effect of treatment.

In conclusion, sarcopenia assessment might be an additional prognostic indicator with conventional biomarkers to optimize the selection criteria for receiving RFA for early-stage HCC. Future studies with a larger sample size and longer follow-up are vital to confirm the prognostic significance of sarcopenia in HCC patients receiving different treatment modalities.

\section{Disclosure}

The authors report no conflicts of interest in this work.

\section{References}

1. Bray F, Ferlay J, Soerjomataram I, Siegel RL, Torre LA, Jemal A. Global cancer statistics 2018: GLOBOCAN estimates of incidence and mortality worldwide for 36 cancers in 185 countries. CA Cancer J Clin. 2018;68:394-424. doi:10.3322/caac.21492

2. Marrero JA, Kulik LM, Sirlin CB, et al. Diagnosis, staging, and management of hepatocellular carcinoma: 2018 practice guidance by the American Association for the Study of Liver Diseases. Hepatology. 2018;68:723-750. doi:10.1002/hep.29913

3. Salati U, Barry A, Chou FY, Ma R, Liu DM. State of the ablation nation: a review of ablative therapies for cure in the treatment of hepatocellular carcinoma. Future Oncol. 2017;13:1437-1448. doi:10.2217/fon-2017-0061

4. Shiina S, Tateishi R, Arano T, et al. Radiofrequency ablation for hepatocellular carcinoma: 10-year outcome and prognostic factors. Am J Gastroenterol. 2012;107:569-77; quiz 578. doi:10.1038/ ajg.2011.425

5. Kim Y, Lim HK, Rhim H, et al. Ten-year outcomes of percutaneous radiofrequency ablation as first-line therapy of early hepatocellular carcinoma: analysis of prognostic factors. J Hepatol. 2013;58:89-97. doi:10.1016/j.jhep.2012.09.020

6. Yang W, Yan K, Goldberg SN, et al. Ten-year survival of hepatocellular carcinoma patients undergoing radiofrequency ablation as a first-line treatment. World J Gastroenterol. 2016;22:2993-3005. doi:10.3748/wjg.v22.i10.2993 
7. Cruz-Jentoft AJ, Sayer AA. Sarcopenia. Lancet Elsevier. 2019;393:2636-2646. doi:10.1016/S0140-6736(19)31138-9

8. Otten L, Stobäus N, Franz K, et al. Impact of sarcopenia on 1-year mortality in older patients with cancer. Age Ageing Oxford Acad. 2019;48:413-418. doi:10.1093/ageing/afy212

9. Nakanishi R, Oki E, Sasaki S, et al. Sarcopenia is an independent predictor of complications after colorectal cancer surgery. Surg Today. 2018;48:151-157. doi:10.1007/s00595-017-1564-0

10. Zhang X-M, Dou Q-L, Zeng Y, Yang Y, Cheng ASK, Zhang -W-W. Sarcopenia as a predictor of mortality in women with breast cancer: a meta-analysis and systematic review. BMC Cancer. 2020;20:172. doi:10.1186/s12885-020-6645-6

11. Cruz-Jentoft AJ, Landi F, Schneider SM, et al. Prevalence of and interventions for sarcopenia in ageing adults: a systematic review. Report of the International Sarcopenia Initiative (EWGSOP and IWGS). Age Ageing. 2014;43:748-759. doi:10.1093/ageing/afu115

12. Janssen I, Heymsfield SB, Ross R. Low relative skeletal muscle mass (sarcopenia) in older persons is associated with functional impairment and physical disability. $J$ Am Geriatr Soc. 2002;50:889-896. doi:10.1046/j.1532-5415.2002.50216.x

13. Argilés JM, Busquets S, Stemmler B, López-Soriano FJ. Cachexia and sarcopenia: mechanisms and potential targets for intervention. Curr Opin Pharmacol. 2015;22:100-106. doi:10.1016/j. coph.2015.04.003

14. Eriksson S, Nilsson JH, Strandberg Holka P, Eberhard J, Keussen I, Sturesson C. The impact of neoadjuvant chemotherapy on skeletal muscle depletion and preoperative sarcopenia in patients with resectable colorectal liver metastases. HPB (Oxford). 2017;19:331-337. doi:10.1016/j.hpb.2016.11.009

15. Farhangfar A, Makarewicz M, Ghosh S, et al. Nutrition impact symptoms in a population cohort of head and neck cancer patients: multivariate regression analysis of symptoms on oral intake, weight loss and survival. Oral Oncol. 2014;50:877-883. doi:10.1016/j. oraloncology.2014.06.009

16. Marasco G, Serenari M, Renzulli M, et al. Clinical impact of sarcopenia assessment in patients with hepatocellular carcinoma undergoing treatments. J Gastroenterol. 2020;55:927-943. doi:10.1007/ s00535-020-01711-w

17. Bruix J, Sherman M. Management of hepatocellular carcinoma: an update. Hepatology. 2011;53:1020-1022. doi:10.1002/hep.24199

18. Meza-Junco J, Montano-Loza AJ, Baracos VE, et al. Sarcopenia as a prognostic index of nutritional status in concurrent cirrhosis and hepatocellular carcinoma. J Clin Gastroenterol. 2013;47:861-870. doi:10.1097/MCG.0b013e318293a825

19. Mitsiopoulos N, Baumgartner RN, Heymsfield SB, Lyons W, Gallagher D, Ross R. Cadaver validation of skeletal muscle measurement by magnetic resonance imaging and computerized tomography. J Appl Physiol. 1998;85:115-122. doi:10.1152/jappl.1998.85.1.115

20. Mourtzakis M, Prado CMM, Lieffers JR, Reiman T, McCargar LJ, Baracos VE. A practical and precise approach to quantification of body composition in cancer patients using computed tomography images acquired during routine care. Appl Physiol Nutr Metab. 2008;33:997-1006. doi:10.1139/H08-075

21. Martin L, Birdsell L, Macdonald N, et al. Cancer cachexia in the age of obesity: skeletal muscle depletion is a powerful prognostic factor, independent of body mass index. J Clin Oncol. 2013;31:1539-1547. doi:10.1200/JCO.2012.45.2722

22. Abd-Elsalam S, Elwan N, Soliman H, et al. Epidemiology of liver cancer in Nile delta over a decade: a single-center study. South Asian J Cancer. 2018;7:24-26. doi:10.4103/sajc.sajc_82_17

23. Canale M, Ulivi P, Foschi FG, et al. Clinical and circulating biomarkers of survival and recurrence after radiofrequency ablation in patients with hepatocellular carcinoma. Crit Rev Oncol Hematol. 2018;129:44-53. doi:10.1016/j.critrevonc.2018.06.017

24. Dasarathy S. Consilience in sarcopenia of cirrhosis. $J$ Cachexia Sarcopenia Muscle. 2012;3:225-237. doi:10.1007/s13539-012-0069-3
25. Chang K-V, Chen J-D, Wu W-T, Huang K-C, Hsu C-T, Han D-S. Association between loss of skeletal muscle mass and mortality and tumor recurrence in hepatocellular carcinoma: a systematic review and meta-analysis. Liver Cancer. 2018;7:90-103. doi:10.1159/ 000484950

26. Prado CMM, Lieffers JR, McCargar LJ, et al. Prevalence and clinical implications of sarcopenic obesity in patients with solid tumours of the respiratory and gastrointestinal tracts: a population-based study. Lancet Oncol. 2008;9:629-635. doi:10.1016/S1470-2045(08)70153-0

27. Thoresen L, Frykholm G, Lydersen S, et al. Nutritional status, cachexia and survival in patients with advanced colorectal carcinoma. Different assessment criteria for nutritional status provide unequal results. Clin Nutr. 2013;32:65-72. doi:10.1016/j.clnu.2012.05.009

28. Voron T, Tselikas L, Pietrasz D, et al. Sarcopenia impacts on shortand long-term results of hepatectomy for hepatocellular carcinoma. Ann Surg. 2015;261:1173-1183. doi:10.1097/SLA.0000000000 000743

29. Harimoto N, Shirabe K, Yamashita Y-I, et al. Sarcopenia as a predictor of prognosis in patients following hepatectomy for hepatocellular carcinoma. Br J Surg. 2013;100:1523-1530. doi:10.1002/ bjs. 9258

30. Iritani S, Imai K, Takai $\mathrm{K}$, et al. Skeletal muscle depletion is an independent prognostic factor for hepatocellular carcinoma. J Gastroenterol. 2015;50:323-332. doi:10.1007/s00535-014-0964-9

31. Itoh S, Shirabe K, Matsumoto Y, et al. Effect of body composition on outcomes after hepatic resection for hepatocellular carcinoma. Ann Surg Oncol. 2014;21:3063-3068. doi:10.1245/s10434-014-3686-6

32. Levolger S, Vledder MG, Van, Muslem R, et al. Sarcopenia impairs survival in patients with potentially curable hepatocellular carcinoma. J Surg Oncol. 2015;112:208-213. doi:10.1002/jso.23976

33. Yuri Y, Nishikawa H, Enomoto H, et al. Implication of psoas muscle index on survival for hepatocellular carcinoma undergoing radiofrequency ablation therapy. $J$ Cancer. 2017;8:1507-1516. doi:10.7150/ jca. 19175

34. Yeh W-S, Chiang P-L, Kee K-M, et al. Pre-sarcopenia is the prognostic factor of overall survival in early-stage hepatoma patients undergoing radiofrequency ablation. Medicine. 2020;99:e20455. doi:10.1097/MD.0000000000020455.

35. Sinclair M, Gow PJ, Grossmann M, Angus PW. Review article: sarcopenia in cirrhosis-aetiology, implications and potential therapeutic interventions. Aliment Pharmacol Ther. 2016;43:765-777. doi:10.1111/apt.13549

36. Vitale G, Cesari M, Mari D. Aging of the endocrine system and its potential impact on sarcopenia. Eur J Intern Med. 2016;35:10-15. doi:10.1016/j.ejim.2016.07.017

37. Gielen E, O'Neill TW, Pye SR, et al. Endocrine determinants of incident sarcopenia in middle-aged and elderly European men. J Cachexia Sarcopenia Muscle. 2015;6:242-252. doi:10.1002/ jcsm. 12030

38. Elmashad N, Ibrahim WS, Mayah WW, et al. Predictive value of serum insulin-like growth factor-1 in hepatocellular carcinoma. Asian Pac J Cancer Prev. 2015;16:613-619. doi:10.7314/APJCP.2015.16.2.613

39. Sachdeva M, Chawla YK, Arora SK. Immunology of hepatocellular carcinoma. World J Hepatol. 2015;7:2080-2090. doi:10.4254/wjh.v7. i17.2080

40. Landi F, Calvani R, Cesari M, et al. Sarcopenia: an overview on current definitions, diagnosis and treatment. Curr Protein Pept Sci. 2018;19:633-638. doi:10.2174/1389203718666170607113459

41. Shen W, Punyanitya M, Wang Z, et al. Total body skeletal muscle and adipose tissue volumes: estimation from a single abdominal cross-sectional image. J Appl Physiol (1985). 2004;97:2333-2338. doi:10.1152/japplphysiol.00744.2004

42. Golse N, Bucur PO, Ciacio O, et al. A new definition of sarcopenia in patients with cirrhosis undergoing liver transplantation. Liver Transpl. 2017;23:143-154. doi:10.1002/1t.24671 
43. Hiraoka A, Aibiki T, Okudaira T, et al. Muscle atrophy as pre-sarcopenia in Japanese patients with chronic liver disease: computed tomography is useful for evaluation. $J$ Gastroenterol. 2015;50:1206-1213. doi:10.1007/s00535-015-1068-x

44. Cabibbo G, Maida M, Genco C, et al. Survival of patients with hepatocellular carcinoma (HCC) treated by percutaneous radio-frequency ablation (RFA) is affected by complete radiological response. PLoS One. 2013;8:e70016. doi:10.1371/journal.pone.0070016
45. Kikuchi L, Menezes M, Chagas AL, et al. Percutaneous radiofrequency ablation for early hepatocellular carcinoma: risk factors for survival. World J Gastroenterol. 2014;20:1585-1593. doi:10.3748/ wjg.v20.i6.1585

46. Waki K, Aikata H, Katamura Y, et al. Percutaneous radiofrequency ablation as first-line treatment for small hepatocellular carcinoma: results and prognostic factors on long-term follow up. $J$ Gastroenterol Hepatol. 2010;25:597-604. doi:10.1111/j.1440-1746.2009.06125.x

\section{Publish your work in this journal}

The Journal of Hepatocellular Carcinoma is an international, peerreviewed, open access journal that offers a platform for the dissemination and study of clinical, translational and basic research findings in this rapidly developing field. Development in areas including, but not limited to, epidemiology, vaccination, hepatitis therapy, pathology and molecular tumor classification and prognostication are all considered for publication. The manuscript management system is completely online and includes a very quick and fair peer-review system, which is all easy to use. Visit http://www.dovepress.com/ testimonials.php to read real quotes from published authors. 